\title{
An Empirical Study on the Comparison between Strategies on Oral English Classes and Writing English Classes
}

\author{
Tsinghong Ma \\ School of Foreign Languages, Shandong Ecnomic University \\ Jinan 250014, China
}

\begin{abstract}
Nowadays, English writing and speaking have received more and more attention at home and abroad. Both scholars and educators have done research on second language learning, especially the learning strategies to facilitate the learning and teaching of English. Among all the branches of English, speaking and writing rank to the most important compared with others.

The present study aims to find out the correlation between the use of speaking and writing strategies of students with poor English. As their English is poor, they have to employ mother tongue to help their speaking and writing of a second language. The subjects of the present study are students in a vocational institute, who wan correlation $t$ to go abroad after two or three years' study there. Therefore, they have strong motivation. This paper investigated the correlation between their language proficiency levels and their use of strategies and found that these two are closely correlated with each other. Besides, the present study also discussed the correlation between different categories of strategies of speaking and writing, and the results show that cognitive, meta-cognitive, social strategies of speaking and writing are closely correlated. All of these give significant implications to the teachers and investigators of second language learning.
\end{abstract}

Keywords: Second language acquisition, Speaking strategies, Writing strategies, Correlation

\section{Introduction}

\subsection{The brief description of the study}

"Language learning strategy" is a popular term nowadays in the field of applied linguistics. Experts both at home and abroad have done researches on the various branches of English, like speaking, listening, writing and so on. As for foreign language learning, speaking and writing are considered to be the most basic and important, so the teaching and learning of these two branches have received much of the attention both from the learners and researchers.

The present study mainly concerns with the correlation between the speaking strategy and the writing strategy used by the first year students in Shandong Commercial and Technical Institute. The subjects are a special group of students as they had got low marks in the college entrance examination and after three years' study, most of them will go abroad for further study. Therefore, their English is really very poor and they have their own language learning and using strategies, especially in terms of speaking and writing owning to their particular characteristics.

As an oral English teacher of these students, the author has found that their speaking strategy is closely related with their writing strategy as when they are speaking, what the usually do is to write an outline or even a short paragraph to remind them what they are going to say, so the writer conducted a research to find out the relation between their use of strategies.

Among the empirical studies on language using strategy, most of the researches are done to find out the strategies used for either speaking or writing, however, not so many researchers investigated the correlation between the strategies of the two. Furthermore, almost all the studies put their emphasis on the normal college students rather than such a special group of students with poor English performance. On account of little exploration in this aspect, the present thesis, inspired by a large number of previous studies, attempts to make the empirical exploration on assessing the relationship between the speaking strategy and the writing strategy to shed some light on our English teaching for those whose English are not so good.

Altogether the whole thesis consists of five chapters. Chapter One briefly introduces the significance of the paper and sketches the main structure of the thesis.

Chapter Two presents a review of the main theories and empirical researches in the field of speaking and writing strategy. 
Chapter Three illustrates the methodology of the thesis. It states the research questions, the subjects, the instruments data collection and data analysis.

Chapter Four is the analyzing chapter. With the aid of statistical software SPSS, it demonstrates the correlation between speaking strategy and writing strategy.

Chapter Five discussed the implication of this study for language teaching and learning as well the limitation of the thesis.

\section{Literature Review}

The study of learning strategies has seen an "explosion of activity" in recent years (Skehan 1991:285, cited in Ellis, 1999:529) and it is not a new topic in teaching and learning researches. In this chapter, the main findings of this research will be examined, and firstly a number of definitions of language strategies and various frameworks of classifying language strategies are offered to us and then it will review the historical studies of language strategy in general and speaking and writing strategy specifically. Finally, there is a summary and evaluation of these studies.

\subsection{Theoretical background}

\subsubsection{Definitions of language strategies}

Language learning strategies refer to all kinds of strategies employed by language learners for efficient learning. However, there has not been an agreement on the definition of this term since various definitions have been given from different perspectives. Ellis (1999:529) says that the concept of strategy is somewhat fussy and it is not easy to tie down. He has listed come classical definitions of the experts, such as Stern (1983), Weinstein \& Mayer (1986), Chamot (1987), Rubin (1987) and Oxford (1989) in his book (1999:531).

According to Ellis, these definitions reveal a number of problems. First, it is not clear whether they are to be perceived of as behavioral or as mental, or as both. A second problem concerns the precise nature of the behaviors that are to count as learning strategies. And a third problem is whether learning strategies are to be seen as conscious and intentional or as subconscious. A fourth problem concerns whether learning strategies are seen as having a direct or an indirect effect on inter-language development. Therefore, it is difficult to give a clear definition to language learning strategy and some experts such as Ellis chose to list the feathers of it rather than just give one definition to it to make it easy to understand.

\subsubsection{Classifications of language strategies}

Researches into what learners do to learn a language has resulted in the identification of specific strategies and in attempts to classify them in some way. As the definition of language learning strategy, researchers do not share the same criteria to classify learning strategies adopted by learners. Thus their classifications of language learning strategy vary a lot.

According to Rubin (1981), strategies can be divided into two primary groups and then a number of subgroups. One of the primary groups consists of strategies that directly affect language learning, including clarification, monitoring, memorization, guessing, inductive reasoning, deductive reasoning and practicing. And the other primary group consists of strategies that contribute indirectly to language learning.

Wenden (1983) examined the strategies that adult foreign language learners use in order to direct their own learning. Her focus, therefore, is on what O'Malley and Chamot call meta-cognitive strategies and then identify three general categories of self-directing strategies.

O'Malley (1985) distinguished three types of strategies that are the basic framework of language learning strategy in many researches, including meta-cognitive, cognitive and social/affective strategies, which is well recognized in the last decades.

Finally, Oxford (1990) distinguishes strategies between direct and indirect strategies and she further explains the relation among different strategies according to O'Malley's classification.

\subsection{Historical researches on language learning strategies}

The representatives of early language learning strategy studies are Rubin, Naiman and Stern. As one of the most influential researchers, Rubin tried to identify the learning strategies employed by the "good language learner" while learning a second language by means of classrooms observation, interview and questionnaire. The framework developed by O'Malley and Chamot, Cohen, and (in particular) Oxford, provide a basis for studying which strategies or combination of strategies are effective in promoting language learning.

Nowadays, two classification schemes are more frequently adopted (Chen Xiao- Tang \& Zheng Min, 2002:35-36). The first one is that according to the role that strategies play in the learning process, there are cognitive strategies, meta-cognitive strategies, affective strategies and communicative strategies. The second one is that according to areas of language knowledge and language skills, there are strategies for learning pronunciation, grammar, vocabulary and 
strategies for developing listening, speaking, reading and writing skills.

\subsection{Historical studies on the speaking and writing strategies}

\subsubsection{Historical studies on speaking strategies}

The empirical studies on oral English learning strategies are mainly around five topics, respectively, the relationship between learning strategies and the oral English proficiency level, like Huang \& Van Naerssen; the varieties of communication strategies used by students, like Chen Siqing; the relationship between English proficiency level and the communication strategies, like Shen Guohuan; factors influencing the use of communication strategies, and the effectiveness of the training of communication strategies (Wen Qiufang \& Wang Lifei, 2004).

It is worth noting that almost all these studies are concerned with the university students rather than some special group of learners, like adult English learners or students with poor English who entered the university with special purposes or some other reasons.

\subsubsection{Historical studies on writing strategies}

Researches on English writing mainly involves five categories, that is, writing theories, writing processes, text, affecting factors and pedagogy. In the past decade, scholars and educators sue different methods such as thinking-aloud, questionnaire, text-analyzing and case study to carry out a large number of empirical and experimental researches. The role of L1 in L2 learning has always been the focus of many researches (Guo Chunjie \& Liu Fang, 1997; Wen Qiufang \& Guo Chunjie 1998; Wang Wenyu \& Wen Qiufang, 2002), and they studied the process of L2 writing of Chinese students by the method of thinking-aloud to determine the function of L1 in L2 writing. Besides, other researches also discovered that Chinese students tended to use informal expressions in their writing and this tendency weakened with the growth English proficiency. It was concluded that the most prominent problem of L2 writing in China was that students' English was poor, so most of them wrote with the help of L1.

\subsubsection{Evaluation and summary}

From the above we can see that the previous studies on English speaking and writing are mainly focused on the correlation between the language competence and the English proficiency and influencing factors, and the subjects are mainly university students. However, for some special group of students, like those who got low marks in the college entrance examinations but entered the university for special purposes, such as going abroad, their English is poor. And the writer found that when the teacher asked them to have a group discussion or prepare a speech, what they usually do is to write a small composition and then read it out. So, there is some correlation between their speaking and writing strategies. Based on this hypothesis, the writer conducted this research and wanted to find out some useful information and implication to the teaching of these students.

\subsection{Transfer of native language}

Language transfer has long been a controversial topic in applied linguistics, second language acquisition and language teaching for many years. Within the last few decades, its importance in foreign language learning has been reassessed several times. Now, the study of language transfer has again become a hot issue in SLA.

Language transfer, in the learning theory of psychology, refers to the influence of a learner's previous linguistic knowledge, mainly that of native language, on the learning of a new language. In terms of its functions, facilitation or interference, language transfer is further dichotomized into positive transfer and negtive transfer. in language learning, if transfer makes learning easier, or helps second language learning, it is positive transfer; if a patter of rule in first language results in an error or in appropriate form can regarded as the result of negtive transfer in interference (Ringbom, 1987:58)

\section{Methodology}

\subsection{Research questions}

The main purpose of the present study is to investigate the relationship between the speaking and writing strategies. It is designed to answer the following questions:

(1) How do the speaking strategies correlate with the writing strategies for those whose English is poor but want to learn well for some special purposes.

(2) Is there any correlation between language proficiency and language strategy use by the students?

(3) To what extent do the speaking strategies correlate with the writing strategies?

(3) Is there any correlation between different writing strategies and their corresponding categories of speaking strategies?

\subsection{Subjects}

The participants of the study are 50 first year college students in Shan dong Commercial and Technical institute. They are a special group of students as they didn't do well in the college entrance examination, some even got the lowest 
marks, so their English was poor but they wanted to go abroad when they graduate from the university. Among the tests collected, 43 are valid, and the other four are excluded because some of the participants forgot to write their identity numbers and others missed some terms of the questionnaire. Of the remaining 43 participants, they are from the same class, so the learning environment is also the same.

\subsection{Instruments}

The instrument used in the study includes two questionnaires, one is about English speaking strategies and the other is about the writing strategies. And then an oral English test.

The questionnaire about speaking strategies consists of two parts, the background information and a modified version of Oxford's ESL/EFL SILL which was translated into Chinese.

The questionnaire about writing strategies has the same structure as the speaking strategies to make it easy to analyze. Besides, although there are various classifications of strategies, both the two questionnaires about speaking and writing are classified according to the same criteria, therefore, it is easier and better to analyze the correlation between them.

Then, the writer had an interview with three students of the subjects, and asked them what they usually do when they are preparing for speaking. All of these three students told that they employ the strategies of writing first, as they usually write what they want to say and then translate them to oral English.

Finally, an oral test is given to them as their final oral English examination, that is, the learning result of a term. Combining the questionnaires and the oral test, we can between understand the relationship between these two kinds of strategies.

\subsection{Data collection and analysis}

After the scoring of the data, all the raw data were put into the computer for statistical analysis, and the software utilized to process the data was SPSS 10.0. As the purpose of the study is to investigate the relationship between speaking strategies and the writing strategies, Pearson correlations are the dominant techniques for the statistical analysis.

\section{Results and Discussion}

This chapter presents us the results or answers put forward in the past chapter. As is mentioned above, the main techniques used in this paper are t-test and correlation, so this chapter is organized according to the questions.

\subsection{Correlations between language proficiency level and the strategy use of the students}

\subsubsection{Correlations between language proficiency level and the writing strategy use Table 1}

\section{Insert Table 1 Here}

Table 1 shows us that language proficiency level is closely correlated with the use of writing strategies. The Pearson correlation is .409 and the significance is 0.006 , which means that there is close correlation between language proficiency level and the use of writing strategies.

\subsubsection{Correlations between language proficiency level and the writing strategy use}

Insert Table 2 Here

Table 1 shows us that language proficiency level is closely correlated with the use of speaking strategies. The Pearson correlation is .311 and the significance is 0.043 , which means that there is close correlation between language proficiency level and the use of speaking strategies.

To sum up, language proficiency is closely related to the strategy use. Students with high proficiency level tend to use more language strategies than those with low proficiency level. Therefore, teachers had better organize those students who have high language proficiency level to share their experiences with those who have low proficiency levels. This is more effective than teachers teach them.

\subsection{Correlations between the use of speaking strategies and writing strategies}

\section{Insert Table 3 Here}

As we mentioned above, the subjects of this paper are students whose English is very poor, and when they speak English, what they usually do is to write what they want to say and then speak. Therefore, there are some similarities between their speaking strategies and writing strategies. From table 3, we can see that their writing strategies are closely related to their speaking strategies. In a sense, their oral English is a part of their writing in that they speak what they have written. The significance of correlation is 0.000 , which means the close relation between these two.

So, the teacher of such kind of students should improve their basic english proficiency level, and then combine the teaching of writing and speaking together at the beginning, which is good for their initial learning of English. 


\subsection{Comparison between different categories of writing English and their corresponding categories of spoken English}

Insert Table 4 Here

Insert Table 5 Here

As is shown from the above two tables, among all the categories of language writing and speaking strategies, cognitive strategies, meta-cognitive strategies, affective strategies and social strategies of writing and speaking have close correlations, which means that there are similarities between students' use of different categories of speaking and writing strategies. As for affective strategy, there appears no significant correlation perhaps due to the overall low proficiency level of all the students. Therefore, teachers should take this into consideration when they teach writing and speaking.

\subsection{The results of the interview about the use of strategies}

The writer interviewed ten students before they had their final oral examination. All of them told that they firstly write what they want to say, in English or Chinese. We should note that what the students wrote here is not a simple outline, but almost all the sentences or key words of the sentences as they said that they just do what they usually before they write something. As their answer is almost the same, here the writer only gives two answers which can represent all the others' ideas.

Question: how do you usually do when you prepare your speech? What is the difference between speaking and writing of English?

Subject: I usually write what I want to say on papers, in which I can read them out to prevent forgetting them. Because my English is not good, so I always write them in Chinese, and then translate them into English by using a dictionary or ask the teacher or classmates for help. Speaking is speaking out what we have written, but writing is just putting your ideas on the paper.

Subject 2: I usually write in Chinese what I want to say, but only the beginning and the end of the whole. As for the middle part, I usually write the key words or phrases, and then when I ' $\mathrm{m}$ speaking, I can organize them into sentences. There are no other differences between speaking and writing but one is in written form and the other is in oral form.

In short, almost all the subjects think that oral English is just speaking out what they have written, and they have not recognized the major differences between these two cognitively separate branches of learning. Therefore, they do not know the difference between them lies in different registers, that is, one is mainly spoken language and the other is written language. This can also explain why all of them write what they want to say first and then read them out as their oral English.

\section{Conclusion and Implication}

\subsection{Limitations of the present study and recommendations for further research}

Although this study was designed to examine the correlation between oral English strategies and writing strategies employed by a special group of students whose English is poor and gained some useful information from it, the limitations of this study should not be ignored.

Firstly, the sample is relatively small and the proficiency and background of the subjects are various. Therefore, it may fail to present the general situation of the large number of all learners with such background.

Secondly, the way the writer processes the data from the two written questionnaires is not rigorous which may influence the result of the study.

Thirdly, some specific strategies in the questionnaire may fail in representing the strategies that the subjects use. They use other strategies which are not included in the present questionnaire. If so, the result of the study may not objectively express the real situation of the strategy use.

\subsection{Major findings and implications for language teaching}

This paper investigates the correlation between the use of oral English strategies and the writing strategies. From this study, we can see that there is close correlation between the different uses of these two kinds of strategies.

Firstly, we can see from the present study that language strategy use is closely related to language proficiency level, therefore teachers of writing and speaking should pay great attention to improve the overall English proficiency level if these students' English is poor. Only in this way, these students can use the strategies more effectively, and then improve their speaking and writing achievement.

Secondly, as their English is quite poor, they tend to employ translation as one of the most useful tools when they want to speak or write something. Even for those whose English is quite well, it is common for them to use mother tongue to learn a second language. Besides, this study also proves this fact. Then what the teachers should do is to combine the teaching of writing and speaking together. Nowadays, it is well known that mother tongue plays both a positive and a 
negtive role in second language learning, and the role of it in second language learning is in hot dispute. However, here, for the teaching of writing and speaking to those whose english is not so good, it is good for the teachers to make good use of mother tongue. This is also why the writer wants to compare these two different cognitive branches of learning.

Thirdly, as for the teaching of writing and speaking, teachers can first give students a topic for them to discuss or compose, and then ask them to think out or write an outline, and then speak what they write to the whole class, and finally, ask the students to write a paragraph or a small composition to help them recognize their shortcomings of the previous speaking, like mistakes or errors, which is more effective for both of their writing and speaking. However, when their language proficiency improves, the teachers should avoid such kind of teaching and then teach these two different branches of learning separately.

\section{References}

Cohen, A. (2000). Strategies in Learning and Using a Second Language. Beijing: Foreign language Teaching and Research Press.

Ellis, R. (1997). The Study of Second Language Acquisition. Oxford: Oxford University Press.

Oxford, R.L. (1990). Language Learning Strategies: What Every Teacher Should Know. Rowley, Mass: Newbury House.

Ringbom, H. (1987). The Role of the First Language in Foreign Language Learning. Clevedon, Avon : Multilingual Matters.

Rubin, J. (1981). Study of Cognitive Processes in Second Language Learning. Applied Linguistics, (2)

Wenden, A. (1983). Literature Review: The Process of Intervention. Language Learning.

Cheng Xiaotang and Zheng Min. (2000). English Language Learning Strateties: From Theory to Pratice. Beijing: Foreign language Teaching and Research Press.

Guo Chunjie and Liu Fang. (1997). Dynamic Studies on the Influence of Mother Tongue in Writing in a Foreign Language. Modern Foreign Languages, (4).

Wen Qiufang. (1999). Oral English Testing and Teaching. Shanghai: Shanghai Foreign Language Education Press.

Wen Qiufang and Guo Chunjie. (1998). Relation Between Thinking in Mother Tongue and Writing in a Foreign Language. Modern Foreign Languages, (4).

Wen Qiufang and Wang Lifei. (2004). Twenty Years of Empirical Studies on English Language Learning Strateties in China. Literature in Foreign Languages, (1).

Table 1.

Correlations

$\begin{array}{llll}\begin{array}{l}\text { Scores } \\ \begin{array}{l}\text { Entrance } \\ \text { exam }\end{array}\end{array} & \text { atPearson Correlation } & \begin{array}{l}\text { Scores at Entrance exam } \\ 1.000\end{array} & \begin{array}{l}\text { Writing trategies } \\ .409\end{array} \\ & \text { Sig. (2-tailed) } & . & \\ & \mathrm{N} & 43 & .006 \\ \text { Writing } & \text { Pearson Correlation } & .409 & 43 \\ \text { strategis } & \text { Sig. (2-tailed) } & .006 & 1.000 \\ & \mathrm{~N} & 43 & . \\ & & & \\ & & \end{array}$

** Correlation is significant at the 0.01 level (2-tailed). 


\section{Table 2.}

Correlations

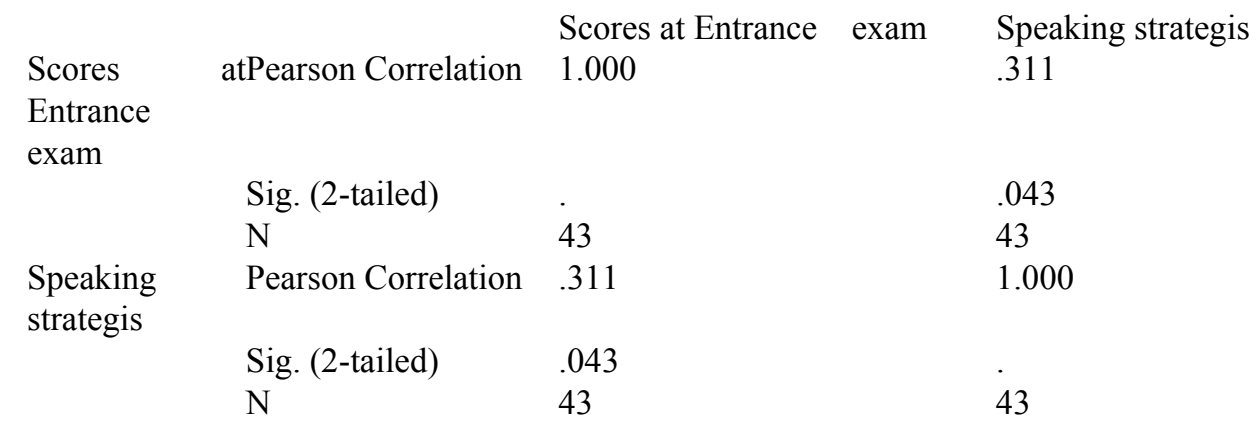

- Correlation is significant at the 0.05 level (2-tailed).

Table 3.

\section{Correlations}

\begin{tabular}{|ll|r|r|}
\hline & & MEANKOU & MEANXIE \\
\hline MEANKOU & Pearson Correlation & 1.000 & $.673^{*}$ \\
& Sig. (2-tailed) &. & .000 \\
& $\mathrm{~N}$ & 43 & 43 \\
\hline MEANXIE & Pearson Correlation & $.673^{*}$ & 1.000 \\
& Sig. (2-tailed) & .000 &. \\
& $\mathrm{~N}$ & 43 & 43 \\
\hline
\end{tabular}

$* *$. Correlation is significant at the 0.01 level

Table 4.

Paired Samples Correlations

\begin{tabular}{|ll|r|r|r|}
\hline & & N & Correlation & \multicolumn{1}{c|}{ Sig. } \\
\hline Pair 1 & KRENZHI \& XRENZHI & 43 & .448 & .003 \\
Pair 2 & KBUCHANG \& XBUCHANG & 43 & .491 & .001 \\
Pair 3 & KQINGGAN \& XQINGGAN & 43 & .246 & .112 \\
Pair 4 & KYUANREN \& XYUANREN & 43 & .767 & .000 \\
Pair 5 & KSHEJIAO \& XSHEJ IAO & 43 & .589 & .000 \\
\hline
\end{tabular}

Table 5.

Paired Samples Test

\begin{tabular}{|c|c|c|c|c|c|c|c|c|c|}
\hline & \multicolumn{5}{|c|}{ Paired Differences } & \multirow[b]{3}{*}{$\mathrm{t}$} & \multirow[b]{3}{*}{ df } & \multirow[b]{3}{*}{ Sig. (2-tailed) } \\
\hline & & \multirow[b]{2}{*}{ Mean } & \multirow[b]{2}{*}{ Std. Deviation } & \multirow{2}{*}{$\begin{array}{l}\text { Std. Error } \\
\text { Mean }\end{array}$} & \multicolumn{2}{|c|}{$\begin{array}{l}\text { 95\% Confidence } \\
\text { Interval of the } \\
\text { Difference }\end{array}$} & & & \\
\hline & & & & & Lower & Upper & & & \\
\hline Pair 1 & KRENZHI - XRENZHI & $7.216 \mathrm{E}-02$ & .4746 & $7.237 \mathrm{E}-02$ & $-7.39 \mathrm{E}-02$ & .2182 & .997 & 42 & .324 \\
\hline Pair 2 & KBUCHANG - XBUCHANG & -.4302 & .5844 & 8.913E-02 & -.6101 & -.2504 & -4.827 & 42 & .000 \\
\hline Pair 3 & KQINGGAN - XQI NGGAN & -.6076 & .7656 & .1167 & -.8432 & -.3720 & -5.204 & 42 & .000 \\
\hline Pair 4 & KYUANREN - XYUANREN & 7.649E-02 & .3777 & 5.760E-02 & $-3.98 \mathrm{E}-02$ & .1927 & 1.328 & 42 & .191 \\
\hline Pair 5 & KSHEJIAO - XSHEJIAO & $1.000 \mathrm{E}-01$ & .5695 & $8.684 \mathrm{E}-02$ & $-7.53 \mathrm{E}-02$ & .2753 & 1.152 & 42 & .256 \\
\hline
\end{tabular}

